www.mdpi.com/journal/remotesensing

Article

\title{
A Water Index for SPOT5 HRG Satellite Imagery, New South Wales, Australia, Determined by Linear Discriminant Analysis
}

\section{Adrian Fisher ${ }^{1,2, *}$ and Tim Danaher ${ }^{1,3}$}

1 Joint Remote Sensing Research Program, School of Geography, Planning and Environmental Management, University of Queensland, St Lucia, QLD 4072, Australia

2 Australian Wetlands, Rivers and Landscapes Centre, School of Biological Earth and Environmental Sciences, University of New South, Wales, Sydney, NSW 2052, Australia

3 Office of Environment and Heritage, P.O. Box 856, Alstonville, NSW 2477, Australia;

E-Mail: tim.danaher@environment.nsw.gov.au

* Author to whom correspondence should be addressed; E-Mail: adrian.fisher@unsw.edu.au; Tel.: +61-2-9385-3393; Fax: +61-2-9385-1558.

Received: 22 September 2013; in revised form: 7 November 2013 / Accepted: 7 November 2013 / Published: 13 November 2013

Abstract: A new water index for SPOT5 High Resolution Geometrical (HRG) imagery normalized to surface reflectance, called the linear discriminant analysis water index (LDAWI), was created using training data from New South Wales (NSW), Australia and the multivariate statistical method of linear discriminant analysis classification. The index uses all four image bands, and is better at separating water and non-water pixels than the two commonly used variations of the normalized difference water index (NDWI), which each only use two image bands. Compared across 2,400 validation pixels, from six images spanning four years, the LDAWI attained an overall accuracy of $98 \%$, a producer's accuracy for water of $100 \%$, and a user's accuracy for water of $97 \%$. These accuracy measures increase to $99 \%, 100 \%$ and $98 \%$ if cloud shadow and topographic shadow masks are applied to the imagery. The NDWI achieved consistently lower accuracies, with the NDWI calculated from the green and shortwave infrared (IR) bands performing slightly better $(91 \%$ overall accuracy) than the NDWI calculated from the green and near IR bands ( $89 \%$ overall accuracy). The LDAWI is now being routinely used on an archive of over 2,000 images from across NSW, as part of an operational environmental monitoring program.

Keywords: SPOT5 HRG; water; linear discriminant analysis 


\section{Introduction}

The classification of water in multispectral satellite imagery is often required to map the distribution, morphology or connectivity of water across large areas. Water classification is also useful for other purposes, such as its exclusion from image processing routines that focus on non-water features. When automated processing is required due to large numbers of images, traditional supervised classification techniques requiring image specific training data are inappropriate, as are unsupervised techniques that require manual selection of parameters. Commonly used water index methods, such as the different versions of the normalized difference water index (NDWI) also require a threshold value to be selected for different images [1-3]. An alternative method is to first normalize all imagery by correcting satellite measurements to surface reflectance values, and then derive an index that uses all dimensions of the data. A single threshold can then be applied across all imagery to classify water pixels. This approach was used to classify water in Landsat Thematic Mapper (TM) and Enhanced Thematic Mapper (ETM+) imagery [4], and the concept could be applied to nearly any multi-spectral imagery with similar bands. Normalization of the image data and the selection of training pixels from across the full range of image conditions are the keys to creating a robust index applicable to a large area and across different time periods.

This paper describes the development and validation of a water classification method, based on using linear discriminant analysis to calculate a multi-dimensional water index, and a comparison of this method with the NDWI. The method was developed for Satellite pour l'Observation de la Terre 5 (SPOT5) High Resolution Geometrical (HRG) data, which is used in a large area, operational earth observation program by the Office of Environment and Heritage (OEH) over New South Wales (NSW), Australia. OEH conduct an annual statewide land cover monitoring project using SPOT5 HRG data, and have an archive of over 2,000 images.

\subsection{Water Indices}

Several different water indices have been used to classify water in remotely sensed imagery, usually by calculating the normalized difference between two bands and then applying a threshold. The NDWI was developed by McFeeters [1] for Landsat Multi-Spectral Scanner (MSS) data and takes the form:

$$
N D W I_{\text {McFeeters }}=\frac{\lambda_{\text {green }}-\lambda_{\text {NIR }}}{\lambda_{\text {green }}+\lambda_{N I R}}
$$

where $\lambda$ is the reflectance in the green or near infrared (NIR) wavelengths. Although other water indices have since been proposed the NDWI is still used successfully to map water [5,6]. It is especially useful in imagery that only has bands measuring in the visible and NIR wavelengths such as QuickBird satelitte imagery [6] or some digital aerial imagery [7].

Gao [2] proposed a different NDWI that was originally intended as an index for the water component of vegetation. It uses the normalized difference between NIR and shortwave-infrared (SWIR) reflectance:

$$
N D W I_{\text {Gao }}=\frac{\lambda_{\text {NIR }}-\lambda_{\text {SWIR }}}{\lambda_{\text {NIR }}+\lambda_{\text {SWIR }}}
$$


A third version of the NDWI was proposed by $\mathrm{Xu}$ [3], using green and SWIR reflectance, which provided better differentiation of water in some urban environments. It takes the form:

$$
N D W I_{X u}=\frac{\lambda_{\text {green }}-\lambda_{\text {SWIR }}}{\lambda_{\text {green }}+\lambda_{\text {SWIR }}}
$$

All three versions of the NDWI range from -1 to 1 due to the normalizing effect of the denominator, with water generally above zero as it usually has higher green reflectance than both NIR and SWIR reflectance, and higher NIR reflectance than SWIR reflectance (Figure 1). The normalization reduces local atmospheric and shadowing effects, so the indices can be calculated from top-of-atmosphere reflectance data. Water classification accuracies greater than $96 \%$ have been achieved using locally selected thresholds for the $\mathrm{NDWI}_{\text {McFeeters, }}$ with the $\mathrm{NDWI}_{\mathrm{Xu}}$ usually performing better due to greater water absorption in the SWIR than NIR wavelengths [2,8-10]. The different NDWI products have also been used as inputs into multi-dimensional classification routines for mapping water and aquatic vegetation from Landsat TM/ETM+ imagery [11] and SPOT5 HRG data [12-14].

Figure 1. The three different versions of the normalized difference water index (NDWI) for a subset of a SPOT5 HRG image, over the coast of New South Wales, Australia.
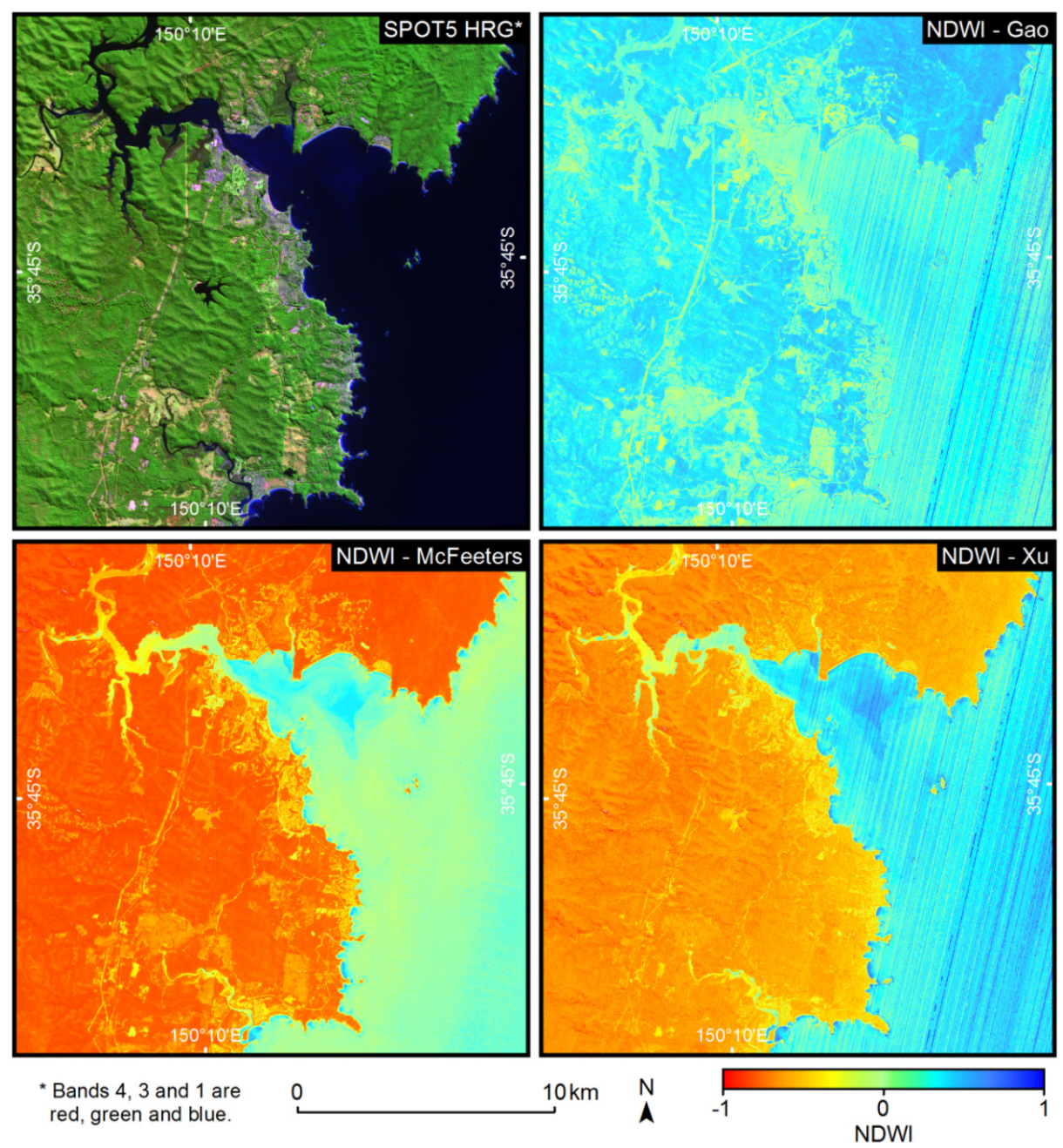

* Bands 4, 3 and 1 are red, green and blue.

0

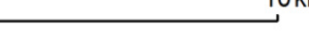

A 
Examining the three NDWI methods for a coastal image containing many water pixels highlights the differences between their ability to separate water and non-water (Figure 1). $\mathrm{NDWI}_{\text {McFeeters }}$ separates water and non-water objects well, with vegetation having a strong negative value and water generally having values greater than zero. The values for water are greater in the $\mathrm{NDWI}_{\mathrm{Xu}}$, although the vegetation response is also greater. The $\mathrm{NDWI}_{\mathrm{Gao}}$ gives very poor separation of water and non-water, with vegetation and water both having strongly positive values. This is to be expected, considering the index was developed for the water component of vegetation.

Tasseled cap transformations of Landsat TM/ETM+ data have also been used to map water $[15,16]$. They attempt to rotate pixel vectors in multi-dimensional space to summarize the data into fewer fundamental views, which present the data structures in the most direct manner [15]. The third fundamental view of the Landsat TM/ETM+ tasseled cap transformation of Crist and Cicone [15] relates to wetness, and tasseled cap wetness (TCW) takes the form:

$$
T C W=\alpha_{1} \lambda_{1}+\alpha_{2} \lambda_{2}+\alpha_{3} \lambda_{3}+\alpha_{4} \lambda_{4}+\alpha_{5} \lambda_{5}+\alpha_{7} \lambda_{7}
$$

where $\lambda_{i}$ is the reflectance value of the $i$ th Landsat TM/ETM+ band, and $\alpha_{\mathrm{i}}$ is the coefficient. The TCW is a water index based on a theoretical data transformation, and was designed to be used with the first (brightness) and second (greenness) fundamental views [15]. While it may be helpful in classifying water in Landsat TM/ETM+ imagery, we suggest that a better multi-dimensional water index can be derived by using multivariate statistics and a suitable set of training data [4].

\section{Method}

\subsection{Data}

NSW is a large $\left(>800,000 \mathrm{~km}^{2}\right)$ state in eastern Australia containing a wide variety of land cover types, including subtropical rainforest, alpine herbfields, and arid shrublands (Figure 2). The state government has purchased several annual statewide coverages of $10 \mathrm{~m}$ resolution SPOT5 HRG imagery, which has the following 4-bands: green $(0.49-0.61 \mu \mathrm{m})$, red $(0.61-0.68 \mu \mathrm{m})$, NIR $(0.78-0.89 \mu \mathrm{m})$ and SWIR $(1.58-1.75 \mu \mathrm{m})$. The SWIR band images are supplied as $10 \mathrm{~m}$ resolution but based on $20 \mathrm{~m}$ resolution sensor. Each annual coverage contains around 340 SPOT5 HRG images, making automated processing essential.

Eight SPOT5 HRG images from 2008 and 2009 were chosen to represent the variety of land and water types across NSW (Figure 2). These included two east coast images, four images from the central-west, one image from the alpine highlands in the south and one from the arid zone in the north west. Water bodies vary greatly across these images, and include ocean, surf, estuaries, rivers, dams, lakes, irrigated fields, and snow (Figure 3). Land also varies considerably, including urban areas, forest, agriculture, mountains and desert. Seven of the eight images also contain clouds and cloud-shadows, which can have similar spectral properties to water in SPOT5 HRG data, and often create difficulties in its classification. 
Figure 2. Location of the SPOT5 HRG images across New South Wales (NSW), Australia, used to train and validate the water classification, over Landsat TM/ETM+ derived foliage projective cover (FPC) [17]. The validation images are irregular shapes as they correspond to the areas of overlap between concurrent SPOT5 HRG data and high resolution imagery captured with a Leica Airborne Digital Sensor (ADS40). Greater FPC values correspond to the humid forests of the east coast, while the semi-arid and arid grasslands, shrublands and woodlands in the west have much lower FPC values. The location of the town of Warren is also shown to the south of the Mt Harris validation image.

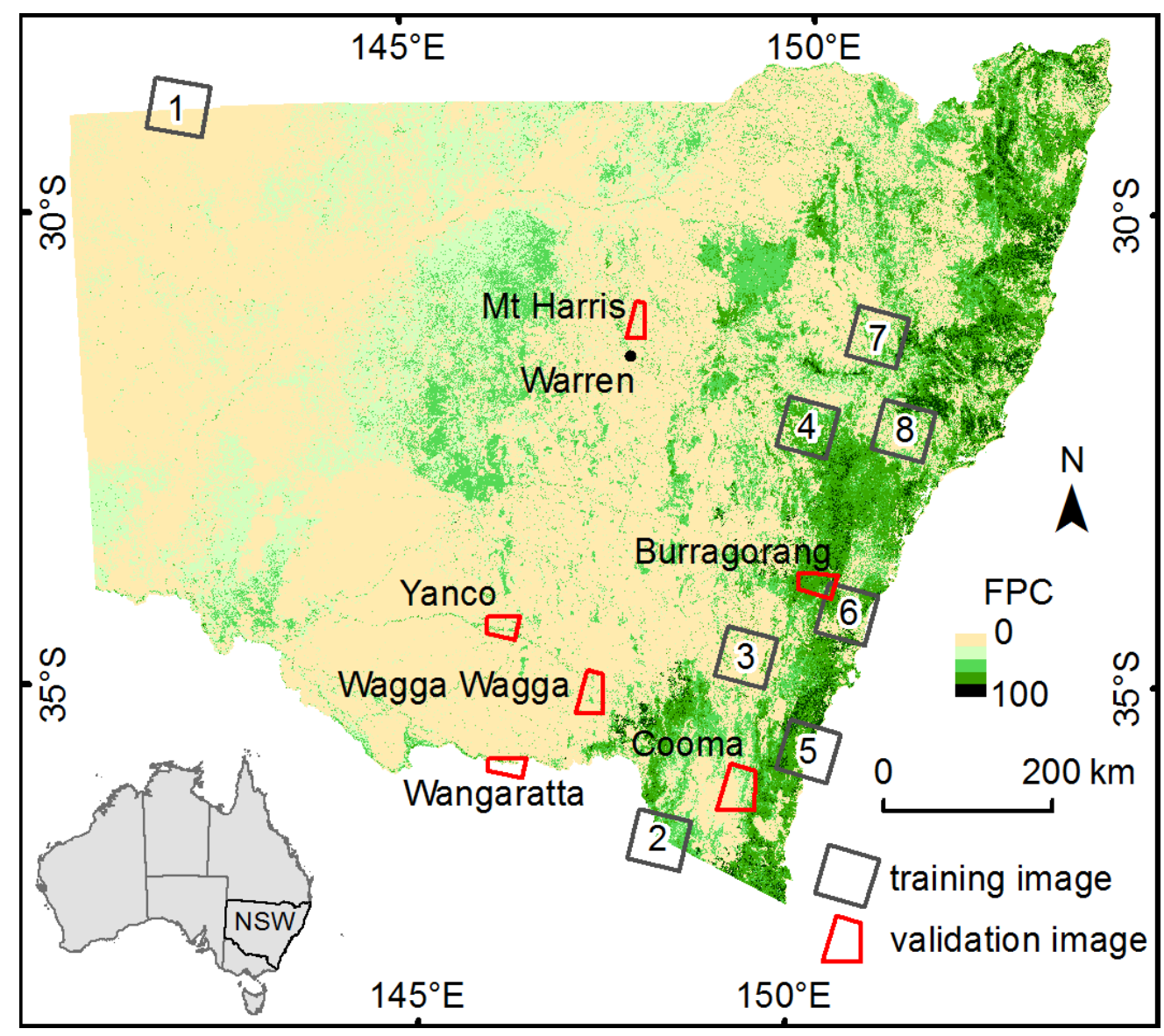

\subsection{Pre-Processing}

The orthorectified images were processed to standardized surface reflectance images [18] with a standard nadir view angle and incidence angle of $45^{\circ}$. This corrected for variations due to atmospheric conditions and the bi-directional reflectance distribution function (BRDF), which also accounted for topographic variations using a $30 \mathrm{~m}$ digital surface model (DSM) [18]. The DSM used was the $1 \mathrm{~s}$ Shuttle Radar Topography Mission [19-21]. Incidence angle (the angle between the sun and the normal to the surface terrain) and exitance angle (the angle between the satellite and the normal to the surface terrain) were also calculated, and pixels with an incidence or exitance angle greater than $80^{\circ}$ were masked from further processing as the BRDF model was not applicable at these angles. Pixels that were shaded by steep topographic features present at the scale of the DSM were also masked by assuming parallel rays of light and using a ray-tracing method [22]. 
Figure 3. Subsets of the training images numbered in Figure 2, showing the variety of water present across New South Wales, Australia. Images are shown with bands 4, 3 and 1 as red, green and blue. Water is present as ephemeral playa lakes (Image 1), snow covered forest (Image 2), small dams close to urban areas (Image 3), rivers within forests (Image 4), coastal estuaries and beaches (Image 5), large dams (Image 6), small dams (Image 7) and rivers within farmland (Image 8).
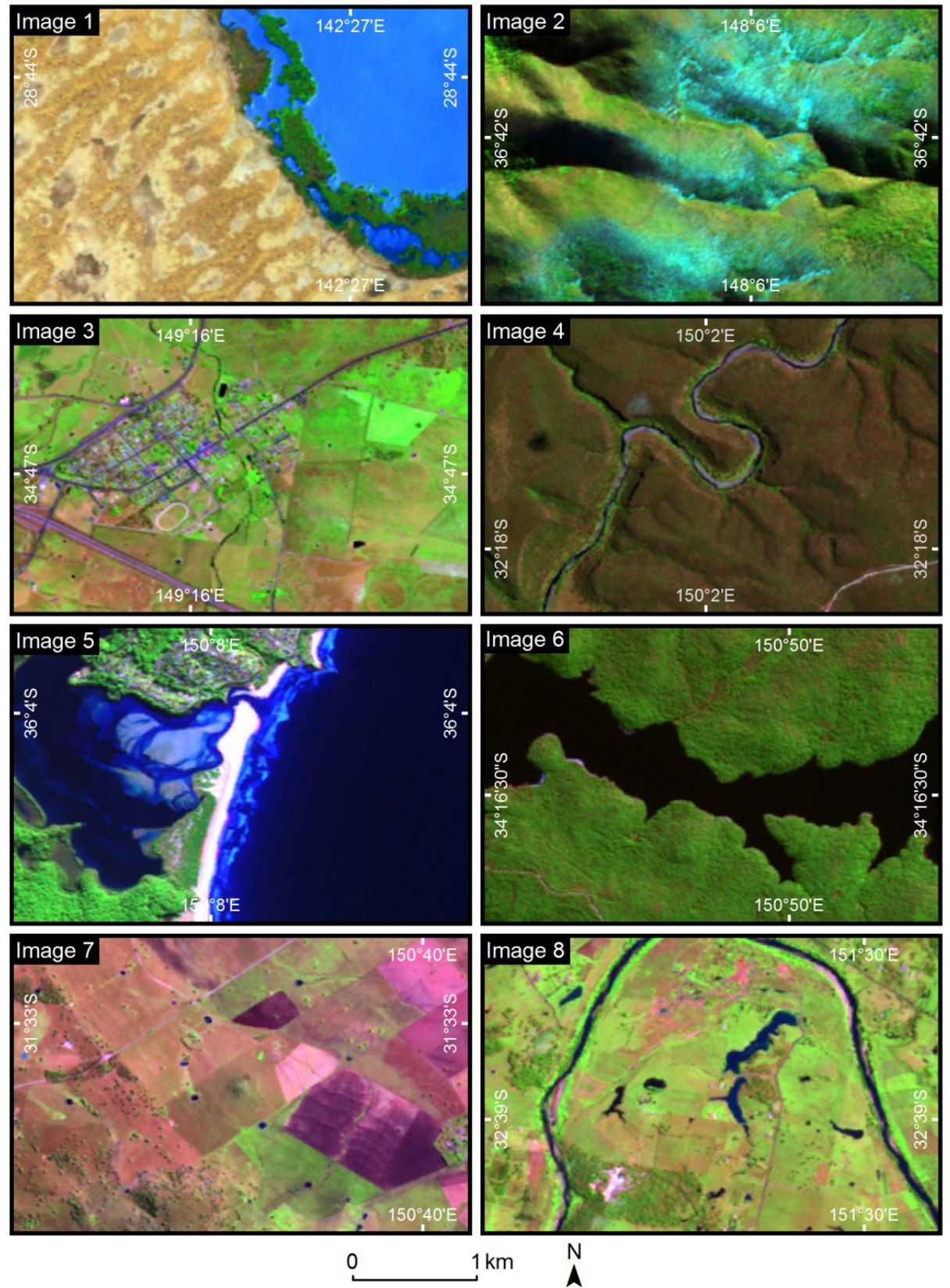

Pixels contaminated by cloud and cloud-shadow were masked with a semi-automated method, which identifies possible cloud and shadow objects and finds those that match based on the size of each object and the distance between them, followed by manual editing to remove errors. A full description of this method is beyond the scope of this paper and will be the subject of a future article. 


\subsection{Training Data}

The eight training images were manually classified into two categories: water and non-water. Water (including snow) was classified by defining marker pixels with a linear threshold in green-SWIR space, and growing segments using the watershed-from-markers algorithm. This method was developed as a simple way of separating most water from cloud-shadows, and it was designed to omit any pixel that might not be water. In order to classify these more difficult water bodies, extra markers were manually added before re-growing the segments. To ensure pixels containing a mixture of water and the surrounding land cover were not used as reference data, a two pixel buffer was established by performing a one pixel morphological erosion on each segment of each class. The buffer region was then masked from the training data.

For each image the surface reflectance values for each classified pixel were extracted and combined, to give a total of nearly 253 million training pixels, comprising 23 million water pixels and 230 million non-water pixels. A sample of one million random pixels were selected from each class and used as training data for the water index calculations. The reflectance values for each class show that water generally has less reflectance in the SWIR than the other bands when compared to non-water pixels, although the two classes have a considerable overlap when viewed in only two dimensions (Figure 4). It is apparent that any two-dimensional classification will result in errors, while the following sections show that a classification based on all four dimensions can achieve a higher degree of accuracy.

Figure 4. Scatter plots of surface reflectance for the training data (1 million water and 1 million nonwater pixels). In order to show the 2-dimensional spectral overlap between classes, each graph was divided into 100 by 100 bins, and the occurrence of water and non-water was calculated for each bin.
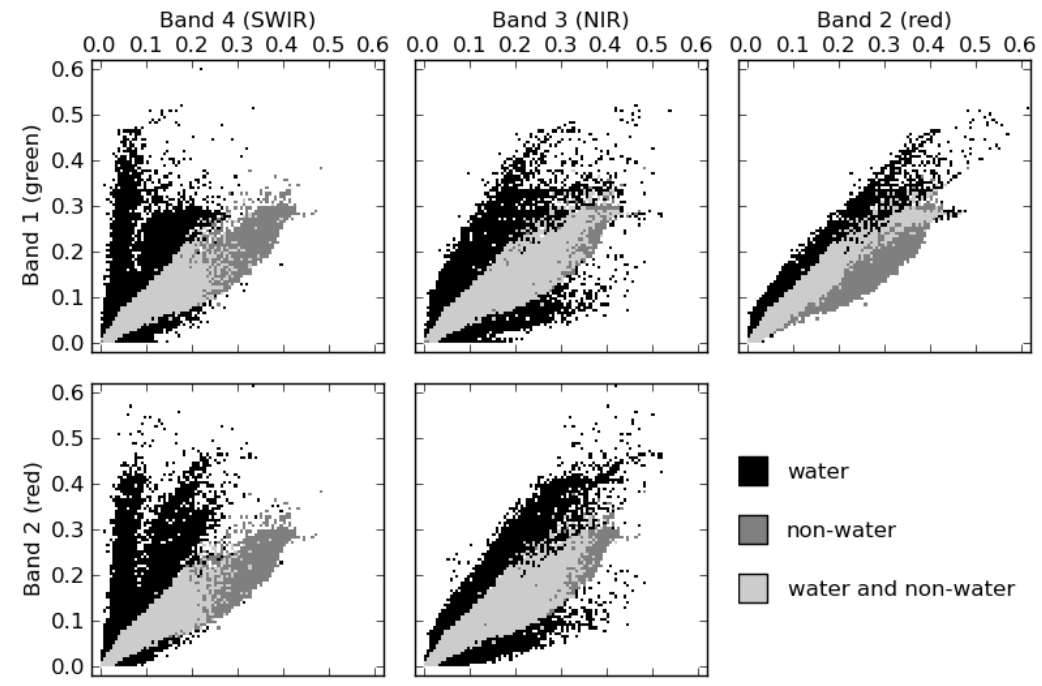

water

non-water

water and non-water

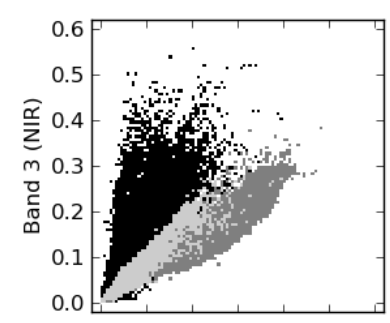




\subsection{Linear Discriminant Analysis Classification}

A multi-dimensional water index was calculated for the SPOT5 HRG data through conducting linear discriminant analysis classification (LDAC) on the training data. LDAC outputs a boundary equation that separates classes in parameter space using a linear combination of the predictor variables. When only two classes are analyzed, such as water and non-water, the boundary equation can be viewed as a linear discriminant analysis water index (LDAWI) where $\alpha$ and $\beta_{i}$ are determined to maximize the separation of the two classes, and the LDAWI threshold value that separates the two classes is zero:

$$
L D A W I=\alpha+\beta_{1} x_{1}+\beta_{2} x_{2}+\cdots+\beta_{n} x_{n}
$$

where $\alpha$ is the intercept, $\beta_{i}$ is the $i$ th coefficient of $n$ terms and $x_{i}$ represents each predictor variable. The predictor variables used were the natural logarithm of each bands surface reflectance, and the interactions of these transformed bands. The logarithm transformation removed much of the skew in the frequency distribution of each band, while the interaction terms allowed the equation to account for relationships between the water index and one band that varied depending on another band.

Analyses were conducted using mlpy, a machine learning python package written by Albanese et al. [23] that incorporates LDAC as formulated by Hastie, et al. [24]. Overall accuracy of the classification scheme determined through 10-fold cross validation of the training data was $99.7 \%$. The values of $\alpha$ and $\beta_{i}$ are given in the Table 1, along with details of the predictor variables.

Table 1. Parameters and predictor variables used in the SPOT5 HRG linear discriminant analysis water index (LDAWI). Predictor variables are calculated from the surface reflectance $(\lambda)$ of each band (green, red, NIR and SWIR), where ln is the natural logarithm.

\begin{tabular}{cccc}
\hline Parameter & Value & Predictor Variable & Value \\
\hline$\alpha$ & 224.14 & & \\
$\beta_{1}$ & -76.18 & $x_{1}$ & $\ln \left(\lambda_{\text {green }}\right)$ \\
$\beta_{2}$ & -18.20 & $x_{2}$ & $\ln \left(\lambda_{\text {red }}\right)$ \\
$\beta_{3}$ & -43.00 & $x_{3}$ & $\ln \left(\lambda_{\text {NIR }}\right)$ \\
$\beta_{4}$ & 96.42 & $x_{4}$ & $\ln \left(\lambda_{\text {SWIR }}\right)$ \\
$\beta_{5}$ & 3.79 & $x_{5}$ & $\ln \left(\lambda_{\text {green }}\right) \times \ln \left(\lambda_{\text {red }}\right)$ \\
$\beta_{6}$ & 16.28 & $x_{6}$ & $\ln \left(\lambda_{\text {green }}\right) \times \ln \left(\lambda_{\text {NIR }}\right)$ \\
$\beta_{7}$ & -6.25 & $x_{7}$ & $\ln \left(\lambda_{\text {green }}\right) \times \ln \left(\lambda_{\text {SWIR }}\right)$ \\
$\beta_{8}$ & 1.54 & $x_{8}$ & $\ln \left(\lambda_{\text {red }}\right) \times \ln \left(\lambda_{\text {NIR }}\right)$ \\
$\beta_{9}$ & -1.14 & $x_{9}$ & $\ln \left(\lambda_{\text {red }}\right) \times \ln \left(\lambda_{\text {SWIR }}\right)$ \\
$\beta_{10}$ & -12.77 & $x_{10}$ & $\ln \left(\lambda_{\text {NIR }}\right) \times \ln \left(\lambda_{\text {SWIR }}\right)$ \\
\hline
\end{tabular}

\subsection{Validation Data}

The results of the water classification were assessed against an independent set of reference pixels, which were manually classified by visual inspection of high resolution imagery. The NSW Government archive contains 124 ADS40 3-band (blue, green and red) $0.5 \mathrm{~m}$ resolution large image mosaics captured between 2007 and 2011. Each mosaic image covers a 1:100,000 map sheet $\left(30^{\prime} \times 30^{\prime}\right)$ and was acquired and processed by Land and Property Information using a Leica ADS40 
airborne digital sensor and industry standard methods. The images were created by orthorectifying, color matching and joining overlapping image strips captured with multiple flight lines acquired over several days. Of these mosaics, 55 were captured over seven days or less, and six were found to overlap spatially and temporally within \pm 1 day of an archived SPOT5 HRG image (Figure 2; Table 2). While these six images span a period of four years, all are summer/autumn images acquired between January and April. They cover a wide range of land cover types, including agricultural land, forested areas, urban areas, large low angle floodplains and more hilly terrain. They also include water bodies of different types, depths and turbidity, including lakes, dams, rivers, ponds, and swamps.

Table 2. Imagery used to validate the LDAWI classification method was chosen from the New South Wales Government archive. Six ADS40 digital aerial mosaics were found to overlap spatially and temporally with SPOT5 HRG images (Figure 1). Only mosaics acquired in $\leq 7$ days were considered, and a temporal overlap was considered adequate if the SPOT5 HRG image was acquired within a day of the ADS40 acquisition starting or finishing.

\begin{tabular}{ccc}
\hline ADS40 Image Name & ADS40 Acquisition Dates & SPOT5 HRG Acquisition Date \\
\hline Yanco & 15 February 2008-17 February 2008 & 18 February 2008 \\
Wangaratta & 25 January 2010-25 January /2010 & 25 January 2010 \\
Wagga Wagga & 15 April 2008-17 April 2008 & 16 April 2008 \\
Mt Harris & 1 March 2008-3 March 2008 & 29 February 2008 \\
Cooma & 3 March 2011-3 March 2011 & 2 March 2011 \\
Burragorang & 31 January 2009-07 February 2009 & 06 February 2009 \\
\hline
\end{tabular}

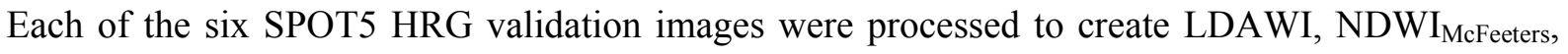
and $\mathrm{NDWI}_{\mathrm{Xu}}$ images. As the $\mathrm{NDWI}_{\mathrm{Gao}}$ was not seen to separate water and non-water (Figure 1) it was not included in the comparison. Validation pixels were randomly selected from the area of overlap with the corresponding ADS40 mosaic. Each sample was stratified, with 200 points having LDAWI values $\geq 0$ and 200 points having LDAWI values $<0$. Each validation pixel was exported as a polygon representing the pixel boundary, overlaid on the ADS40 imagery and manually classified as either water (1,164 pixels) or non-water (1,236 pixels). Polygons containing mixtures of water/non-water were assigned to the dominant class, and the percentage of water was estimated to the nearest $25 \%$, through splitting each polygon into quarters and recording the dominant class of each quarter. LDAWI and NDWI values, both calculated from surface reflectance data, were extracted for each sample pixel to allow each index and classification method to be assessed.

\section{Results and Accuracy Assessment}

\subsection{Linear Discriminant Analysis Water Index}

The validation data show that the LDAWI is able to classify water pixels very well, with water and non-water pixels having substantially different LDAWI distributions (Figure 5). Water pixels have a mean \pm standard deviation LDAWI of $23 \pm 15$, while non-water pixels have $-52 \pm 15$. This separability is also shown if a threshold is applied to the LDAWI to create a classification that can be 
compared to the reference data (Table 3). If the LDAWI threshold is set at zero, which was the value determined by the training data, the overall accuracy, producer's accuracy for water (measure of omission) and user's accuracy for water (measure of commission) are 97.88\%, 99.14\% and 96.57\% respectively. These accuracy measures increase to $98.17 \%, 99.83 \%$ and $96.51 \%$ if the LDAWI threshold is lowered to -10 . This is the optimum LDAWI threshold for the validation data, determined as that which firstly gave the largest overall accuracy and secondly gave the largest producer's accuracy. The improved classification with the lower LDAWI threshold reflects the difference between the training and validation datasets, which is that training pixels were not selected from areas close to the edges of water bodies, while many validation pixels were within two pixels distance from the edges of water bodies. Pixels close to edges often had shallow water, partially submerged woody debris, or shadows from riparian vegetation, which change the reflectance properties of the pixel. Furthermore, 18 validation pixels were not $100 \%$ water or non-water, but were a mixture of the two classes when observed in the ADS40 imagery. Four non-water validation pixels actually contained $25 \%$ water, two of which have LDAWI values greater than zero and are classified as water. Closer inspection of these points reveals that they contained mixtures of water (25\%) and wet soil (75\%), which is likely resulting in reflectance values closer to water than non-water. Five water validation pixels contained $75 \%$ water, and were all classified as water with LDAWI values above zero. Nine water validation pixels contained only 50\% water, eight of which have LDAWI values greater than zero and are classified as water, and one that has a LDAWI value of -19 and is classified as non-water. This pixel is on the edge of a river and does not appear significantly different to the other pixels that contain $50 \%$ water.

Figure 5. Histograms of water index values for the 2,400 validation points, separated into water (black line) and non-water (grey line), for the normalized difference water index of McFeeters $\left(\mathrm{NDWI}_{\mathrm{McFeeters}}\right)$ and $\mathrm{Xu}\left(\mathrm{NDWI}_{\mathrm{Xu}}\right)$, and the linear discriminant analysis water index (LDAWI).
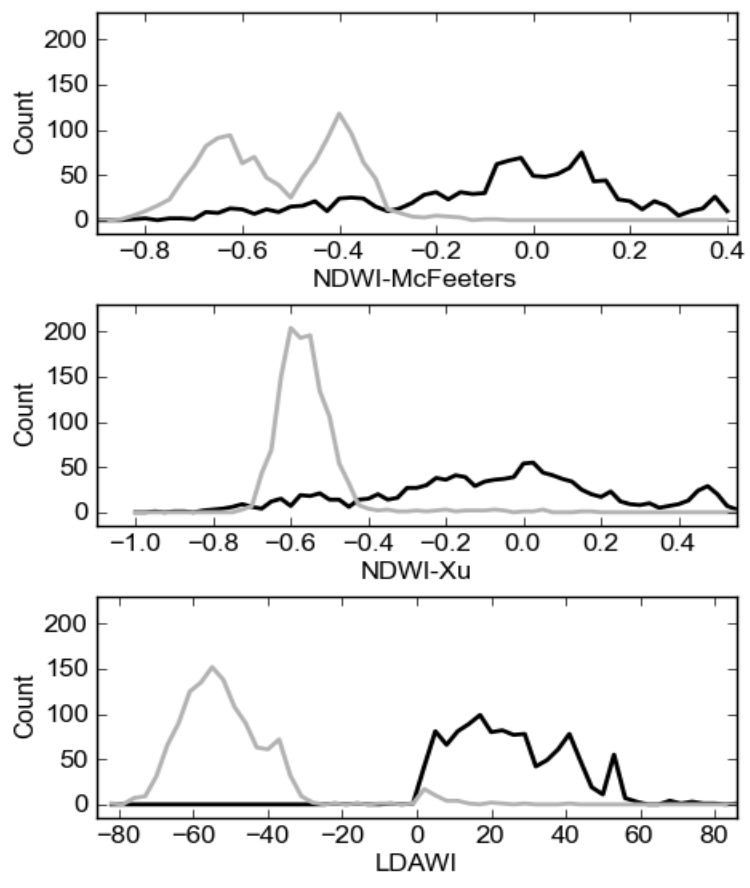
Table 3. Accuracy statistics for water classifications based on the linear discriminant analysis water index (LDAWI) and the normalized difference water index of McFeeters $\left(\mathrm{NDWI}_{\mathrm{McFeeters}}\right)$ and $\mathrm{Xu}\left(\mathrm{NDWI}_{\mathrm{Xu}}\right)$. Statistics were calculated using sample points that were manually classified through high resolution Airborne Digital Sensor (ADS40) image interpretation. Thresholds were determined as the value that firstly gave the greatest overall accuracy, and secondly gave the greatest producer's accuracy. Where a range of threshold values had the same accuracy, the upper and lower values are both shown. LDAWI thresholds were varied by single units, while NDWI thresholds were varied by hundredths of a unit.

\begin{tabular}{|c|c|c|c|c|c|c|}
\hline Index & Image & Threshold & $\begin{array}{c}\text { Sample } \\
\text { Size } \\
\text { (pixels) }\end{array}$ & $\begin{array}{c}\text { Overall } \\
\text { Accuracy } \\
(\%)\end{array}$ & $\begin{array}{c}\text { Producer's } \\
\text { Accuracy for } \\
\text { Water (\%) }\end{array}$ & $\begin{array}{c}\text { Users } \\
\text { Accuracy for } \\
\text { Water (\%) }\end{array}$ \\
\hline \multirow[t]{9}{*}{ LDAWI } & Yanco & $-37--1$ & 400 & 100.00 & 100.00 & 100.00 \\
\hline & Wangaratta & $-22--19$ & 400 & 99.75 & 99.51 & 100.00 \\
\hline & Wagga Wagga & $-9--4$ & 400 & 99.75 & 100.00 & 99.50 \\
\hline & Mt Harris & $-30--1$ & 400 & 96.00 & 100.00 & 92.00 \\
\hline & Cooma & $-36--1$ & 400 & 96.25 & 100.00 & 92.50 \\
\hline & Burragorang & $3-4$ & 400 & 98.25 & 98.96 & 97.44 \\
\hline & Total & -10 & 2,400 & 98.17 & 99.83 & 96.51 \\
\hline & Total, no shadows & -10 & 2,386 & 98.70 & 99.83 & 97.56 \\
\hline & Total, no shadows & -25 & 2,386 & 98.66 & 100.00 & 97.32 \\
\hline \multirow[t]{8}{*}{$\mathrm{NDWI}_{\text {McFeeters }}$} & Yanco & $-0.32--0.31$ & 400 & 99.00 & 98.50 & 99.49 \\
\hline & Wangaratta & -0.30 & 400 & 97.75 & 96.55 & 98.99 \\
\hline & Wagga Wagga & $-0.31--0.29$ & 400 & 96.75 & 95.50 & 97.95 \\
\hline & Mt Harris & -0.33 & 400 & 87.25 & 75.00 & 96.50 \\
\hline & Cooma & -0.54 & 400 & 78.25 & 64.86 & 84.51 \\
\hline & Burragorang & $-0.26--0.24$ & 400 & 98.75 & 97.40 & 100.00 \\
\hline & Total & -0.31 & 2,400 & 88.88 & 79.90 & 96.57 \\
\hline & Total, no shadows & -0.31 & 2,386 & 88.81 & 79.88 & 96.57 \\
\hline \multirow[t]{8}{*}{$\mathrm{NDWI}_{\mathrm{Xu}}$} & Yanco & $-0.45--0.44$ & 400 & 99.75 & 99.50 & 100.00 \\
\hline & Wangaratta & $-0.38--0.27$ & 400 & 97.75 & 96.55 & 98.99 \\
\hline & Wagga Wagga & -0.46 & 400 & 95.75 & 94.00 & 97.41 \\
\hline & Mt Harris & -0.44 & 400 & 94.25 & 94.57 & 93.05 \\
\hline & Cooma & -0.59 & 400 & 71.75 & 60.00 & 74.00 \\
\hline & Burragorang & $-0.43--0.38$ & 400 & 98.25 & 97.92 & 98.43 \\
\hline & Total & -0.45 & 2,400 & 91.25 & 85.91 & 95.60 \\
\hline & Total, no shadows & -0.45 & 2,386 & 91.24 & 85.90 & 95.69 \\
\hline
\end{tabular}

Omission of water pixels was very rare, with only two water pixels being incorrectly classified as non-water when using the optimum threshold of -10 . Even if the threshold is increased to -4 to maximize user's accuracy after overall accuracy, only one extra water pixel is omitted. The two water pixels with LDAWI values lower than -10 have values of -24 and -19 . The first is in shallow water and the second on the edge of a river. If the threshold is lowered to -25 these pixels will be classified as water, which will increase the producer's accuracy to $100 \%$, while only reducing the overall accuracy by $0.04 \%$ and the user's accuracy by $0.24 \%$ (Table 3 ). 
The lower user's accuracy for water classified using the optimum LDAWI threshold of - 10, shows that commission of water pixels is a bigger problem than omission. Commission errors consist of 42 non-water pixels that were falsely classified as water due to land cover types with very similar spectral properties. If a threshold of -4 is used to instead optimize for user's accuracy after overall accuracy, the commission errors are only reduced by one pixel. The errors were caused by quarry sites (16 pixels), cloud shadows ( 8 pixels), wet soil (7 pixels), topographic shadow (6 pixels), buildings ( 2 pixels), parked cars ( 1 pixel) and mixed pixels at the edges of water bodies ( 2 pixels). The largest commission errors are from quarry sites, such as a basalt quarry pit and surrounding gravel stockpiles in the Cooma image. The commission errors can be reduced through applying cloud shadow and topographic shadow masks, increasing the user's accuracy for water to $97.56 \%$ and overall accuracy to 98.70\% (Table 3).

Accuracy statistics for the six individual images are also very high, with all achieving over $96 \%$ overall accuracy and over 98\% producer's accuracy for water using either their individual optimal thresholds or the global optimal threshold of -10 . The Mt Harris and Cooma images have lower user's accuracy for water at $92 \%$ than the other images, which are all greater than $96 \%$. The Cooma image had commission errors mainly due to the basalt quarry. In the Mt Harris image, half the commission errors are due to cloud shadows and can be removed through masking, while the other half are mostly due to wet soil. The image contains many cultivated areas of bare soil, on which it appears rainfall had created very shallow ponds, with some nearby areas having distinct characteristics that are probably due to wet soil. Rainfall records for recording stations close to the nearby town of Warren (Figure 2) show that between 28 and 29 February 2008, 25-62 $\mathrm{mm}$ of rain fell in the Warren area [25]. This corresponds to the day of the SPOT5 HRG capture, which also contains several clouds. The ADS40 data was acquired on the following three days, during which time some of the rainfall would likely have soaked into the bare soil and some would have evaporated.

\subsection{Normalized Difference Water Index}

Although the $\mathrm{NDWI}_{\mathrm{McFeeters}}$ and $\mathrm{NDWI}_{\mathrm{Xu}}$ can separate most water and non-water pixels, the validation data show that they are not as accurate as the LDAWI (Table 3). The NDWI McFeeters values for the non-water validation pixels have a large range (mean \pm standard deviation of $-0.53 \pm 0.14$ ) that overlaps considerably with the values for the water pixels $(-0.09 \pm 0.25)$, especially when compared to the LDAWI (Figure 5). The NDWI $\mathrm{Xu}_{\mathrm{Xu}}$ values for the non-water validation pixels have a better, more narrow distribution $(-0.57 \pm 0.09)$, however the water pixels have a wide range of values $(-0.09 \pm 0.31)$ creating a large overlap and an unclear separation between classes (Figure 5).

If the six $\mathrm{NDWI}_{\mathrm{McFeeters}}$ images are classified into water and non-water using a threshold of -0.31 (to maximize overall accuracy, followed by producer's accuracy), the overall accuracy is $88.88 \%$, the producer's accuracy for water is $79.90 \%$ and the user's accuracy for water is $96.57 \%$ (Table 3 ). The optimal threshold for the $\mathrm{NDWI}_{\mathrm{Xu}}$ images was -0.45 , achieving an overall accuracy of $91.25 \%$, producer's accuracy for water of $85.91 \%$ and user's accuracy for water of $95.60 \%$ (Table 3 ).

Accuracy across the six validation images varies considerably, with the Cooma image having the most errors and only $78 \%$ overall accuracy using the $\mathrm{NDWI}_{\mathrm{McFeeters}}$ and $72 \%$ overall accuracy using the NDWI $\mathrm{Xu}_{\mathrm{Xu}}$ It also has a much lower local optimal threshold, and if the global threshold is applied 
errors increase with overall accuracy at only $56 \%\left(\mathrm{NDWI}_{\mathrm{McFeeters}}\right)$ and $63 \% \mathrm{NDWI}_{\mathrm{Xu}}$. The other images have local optimal thresholds very similar to the global value (Table 3 ).

In contrast to the LDAWI classification, the $\mathrm{NDWI}_{\mathrm{McFeeters}}$ and $\mathrm{NDWI}_{\mathrm{Xu}}$ classifications have greater user's accuracy for water than producer's accuracy for water when using the optimal thresholds. This is mainly caused by the omission of water pixels in the Cooma image. It is not clear why the $\mathrm{NDWI}_{\text {McFeeters }}$ and $\mathrm{NDWI}_{\mathrm{Xu}}$ performed so poorly in the Cooma image, although it also had relatively lower accuracies for the LDAWI. Three examples of small water bodies not detected by the $\mathrm{NDWI}_{\mathrm{McFeeters}}$ or $\mathrm{NDWI}_{\mathrm{Xu}}$ from the Cooma image are shown in Figure 6.

Figure 6. Three examples of where the linear discriminant analysis water index (LDAWI) performs better than the normalized difference water index (NDWI) of McFeeters or Xu in detecting small water bodies, for a subset of the Cooma image (Figure 2).

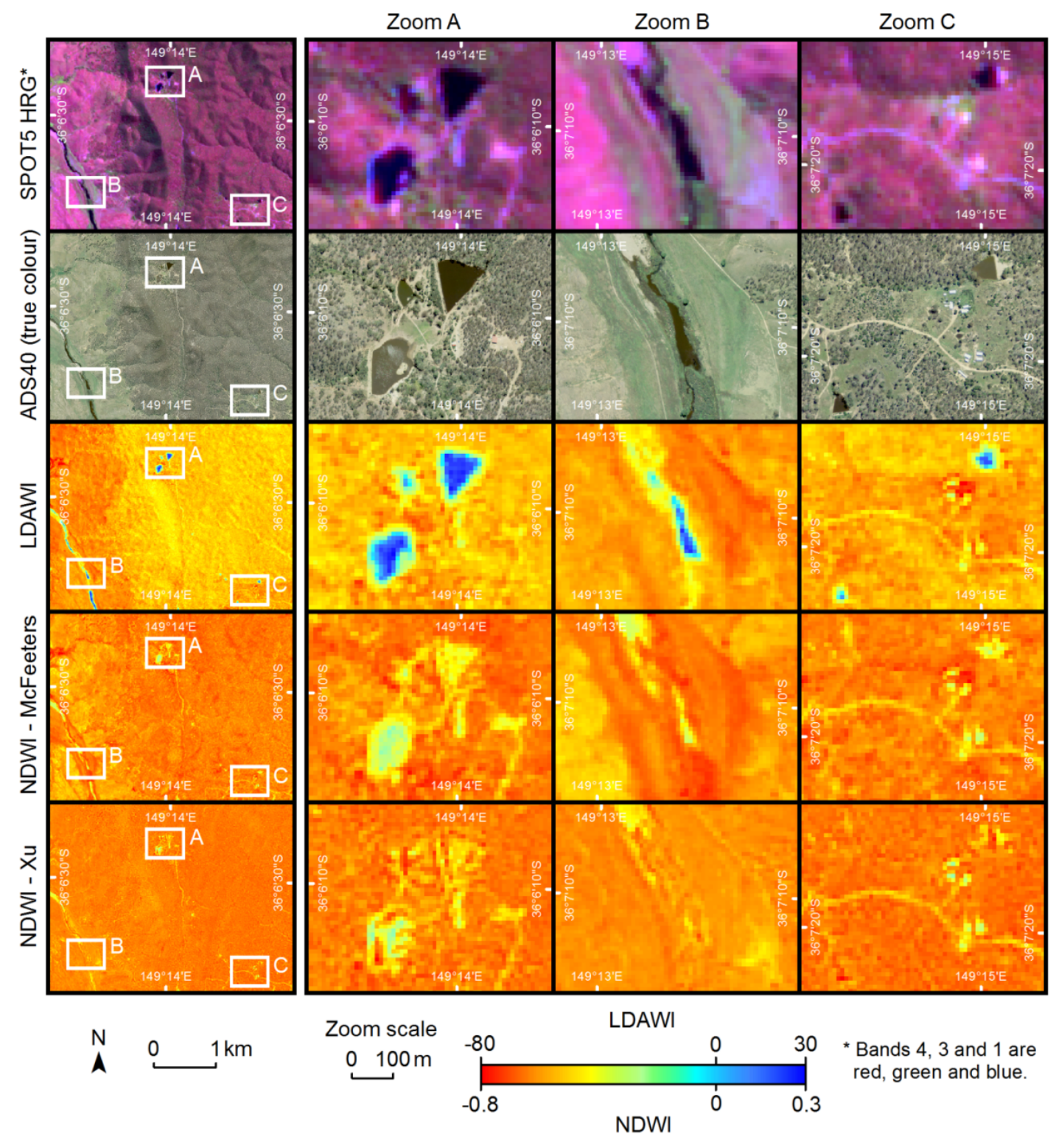


These small water bodies (less than $100 \mathrm{~m}$ wide) are the result of small farm dams and weirs, and are very common across NSW. The LDAWI images show a clear increase over the water bodies, against a background of vegetation, bare soil and urban structures. For some of the water bodies the $\mathrm{NDWI}_{\mathrm{McFeeters}}$ and $\mathrm{NDWI}_{\mathrm{Xu}}$ images show a very subtle increase, with some water pixels being visible. In some cases there is no increase in NDWI value at all, and the water body is not visible.

Of the non-water validation pixels that were classified as water, some errors were similar to the LDAWI classification, such as the quarry sites, wet soil, buildings, parked cars and the edge of a swamp. Other errors were caused by bare soil, trees with tree shadows, crops and vegetation on a lake shore. Cloud shadows and topographic shadows do not cause errors, and applying the shadow masks to the validation data does not increase accuracy. This is the one area where the $\mathrm{NDWI}_{\mathrm{McFeeters}}$ and NDWI $_{\mathrm{Xu}}$ are more accurate than the LDAWI, as shadows often reduce reflectance by the same proportion across the two bands used to calculate the NDWI.

\section{Discussion}

The LDAWI performs very well in classifying a wide variety of water types across NSW, at the $10 \mathrm{~m}$ resolution of SPOT5 $\mathrm{HRG}$ data, and is clearly more accurate than the simpler $\mathrm{NDWI}_{\mathrm{McFeete}}$ or $\mathrm{NDWI}_{\mathrm{Xu}}$. Although the LDAC method optimized the LDAWI parameters from the training data for a threshold of zero, the validation data achieved better overall accuracy when the threshold was lowered to -10 , and producer's accuracy was best when the threshold was -25 . While the validation images did not include any coastal areas, visual inspection of coastal SPOT5 HRG data indicates the LDAWI performs very well in classifying oceans and estuaries (Figure 7). The validation also did not include any snow, which is only present in a small alpine area and does not usually last throughout the Australian summer. Image 2 used in the training data contained some snow, and visual inspection of its LDAWI image showed that it was classified as water (Figure7).

Using an index to classify water, rather than other methods such as classification trees, allows different thresholds to be used when reducing omission errors is considered more important than reducing commission errors. It also allows LDAWI contours to be interpolated to aid interpretation (Figure 8).

The main limitation with the LDAWI is the commission of non-water pixels such as shadows, quarries and buildings. Cloud shadows can be masked out by other means, and are not considered a significant problem as SPOT5 HRG images are not usually purchased with large amounts of cloud. Most topographic shadows can also be masked by using a DSM, although small shadows cast by features not visible at the scale of the DSM $(30 \mathrm{~m})$ cannot be removed. These include shadows from large trees, buildings, and any significant sub-pixel topographic relief, such as small cliffs. These features were a very small proportion of the validation data, although they could cause more errors in images from other areas. Quarries that expose dark rock, stockpiles of gravel and coal and some features of urban areas can also increase errors in the water classification, although these are also usually only present as very small proportions of images. 
Figure 7. Linear discriminant analysis water index (LDAWI) images for the image subsets shown in Figure 3, where water (including snow) is blue and non-water is red. Water is present as ephemeral playa lakes (Image 1), snow covered forest (Image 2), small dams close to urban areas (Image 3), rivers within forests (Image 4), coastal estuaries and beaches (Image 5), large dams (Image 6), small dams (Image 7) and rivers within farmland (Image 8).
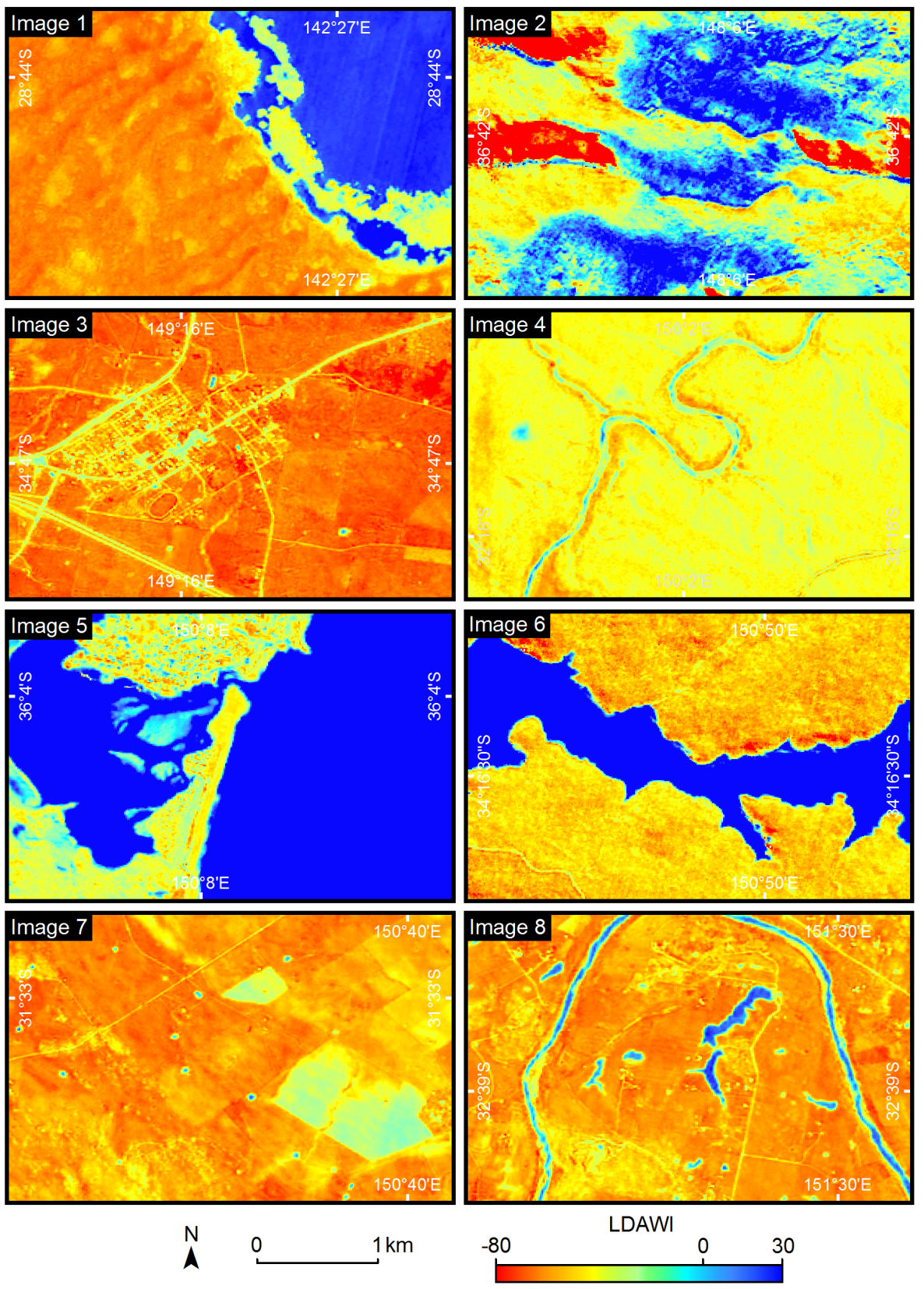

Alternative water index methods, such as the $\mathrm{NDWI}_{\text {McFeeters }}$ or $\mathrm{NDWI}_{\mathrm{Xu}}$ have far more limitations, with greater omission errors resulting in water bodies not being detected. While the LDAWI had a producer's accuracy of around $99 \%-100 \%$ the NDWI had only $80 \%-86 \%$. Small water bodies, such as farm dams, were often seen to have poor separability from the background in NDWI images 
(Figure 6). Although the NDWI $\mathrm{Xu}_{\mathrm{u}}$ calculated from the SWIR band performed slightly better than the $\mathrm{NDWI}_{\text {McFeeters }}$ calculated from the NIR band when compared with the validation data (Table 3), it appears that small water bodies are better defined using the $\mathrm{NDWI}_{\mathrm{McFeeters}}$ (Figure 6). It is likely that these smaller water bodies are not large enough to significantly influence the SWIR band, which is measured at $20 \mathrm{~m}$ resolution rather than the $10 \mathrm{~m}$ resolution of the other bands.

Figure 8. Examples of classifying water using the linear discriminant analysis water index (LDAWI) for rivers, lakes and dams in the six SPOT5 HRG validation images (Figure 1). On the left water is shown using the optimal LDAWI threshold of -10 , overlaid on the source SPOT5 HRG image shown with bands 4, 3 and 1 as red, green and blue. On the right LDAWI values are shown using three interpolated contours overlaid on true color Airborne Digital Sensor (ADS40) imagery.
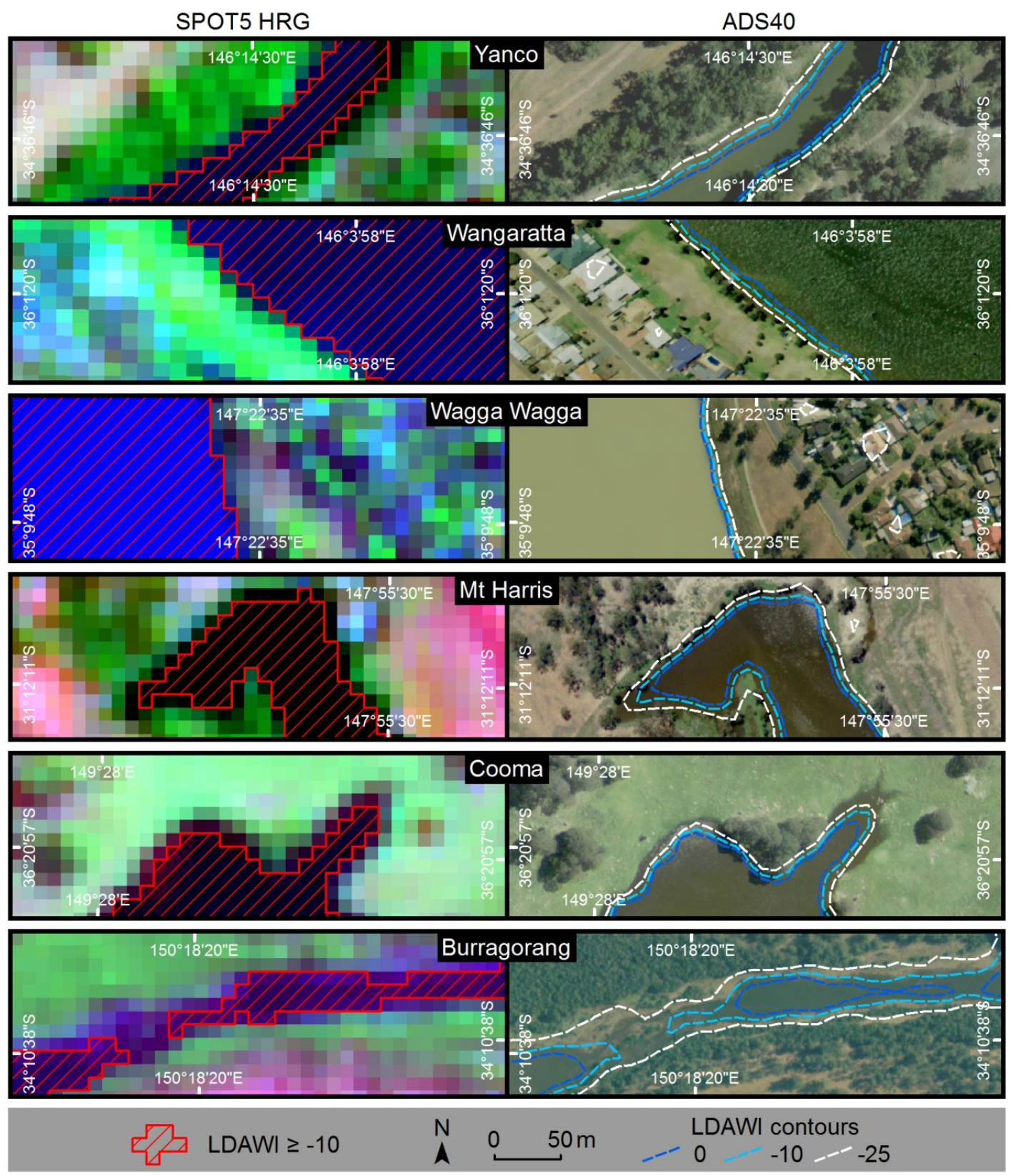


\section{Conclusions}

A linear discriminant analysis water index (LDAWI) was developed for Satellite pour l'Observation de la Terre 5 (SPOT5) High Resolution Geometrical (HRG) satellite imagery over New South Wales (NSW), Australia. The LDAWI combines surface reflectance values from all four bands in an index that is very sensitive to water, and which was able to separate water and non-water pixels with an overall accuracy of $99 \%$. It can be used to detect all types of surface water visible to the satellite, such as ocean, estuaries, lakes, dams, rivers and snow. It is more accurate than the commonly used normalized difference water index (NDWI) of McFeeters [1] or Xu [3], particularly in reducing omission errors caused by the poor detection of small water bodies such as farm dams. The LDAWI has some limitations mainly due to the similarity of water and dark pixels such as shadows. These commission errors are usually a very small proportion of any image, and can be reduced through creating other image masks.

Automatically classifying water with the LDAWI allows it to be excluded from other analyses, facilitating the high resolution statewide vegetation monitoring program conducted by the Office of Environment and Heritage (OEH). It should also prove useful to any analysis of the changing distribution of water across NSW. While the LDAWI is expected to perform well in similar regions, further testing is needed to determine if it is applicable outside NSW.

\section{Acknowledgments}

Thanks to Tony Gill, and three anonymous reviewers for comments that greatly improved the paper.

\section{Conflicts of Interest}

The authors declare no conflict of interest.

\section{References}

1. McFeeters, S.K. The use of the Normalized Difference Water Index (NDWI) in the delineation of open water features. Int. J. Remote Sens. 1996, 17, 1425-1432.

2. Gao, B. NDWI-A normalized difference water index for remote sensing of vegetation liquid water from space. Remote Sens. Environ. 1996, 58, 257-266.

3. $\mathrm{Xu}, \mathrm{H}$. Modification of Normalised Difference Water Index (NDWI) to enhance open water features in remotely sensed imagery. Int. J. Remote Sens. 2006, 27, 3025-3033.

4. Danaher, T.; Collett, L. Development, Optimisation and Multi-Temporal Application of a Simple Landsat Based Water Index. In Proceeding of the 13th Australasian Remote Sensing and Photogrammetry Conference, Canberra, ACT, Australia, 20-24 November 2006.

5. Murray, N.J.; Phinn, S.R.; Clemens, R.S.; Roelfsema, C.M.; Fuller, R.A. Continental scale mapping of tidal flats across east asia using the Landsat archive. Remote Sens. 2012, 4, 3417-3426.

6. McFeeters, S.K. Using the Normalized Difference Water Index (NDWI) within a geographic information system to detect swimming pools for mosquito abatement: A practical approach. Remote Sens. 2013, 5, 3544-3561. 
7. Pai, N.; Saraswat, D. A geospatial tool for delineating streambanks. Environ. Model. Softw. 2013, 40, 151-159.

8. Campos, J.C.; Sillero, N.; Brito, J.C. Normalized Difference Water Indexes have dissimilar performances in detecting seasonal and permanent water in the Sahara-Sahel transition zone. J. Hydrol. 2012, 464-465, 438-446.

9. Soti, V.; Tran, A.; Bailly, J.S.; Puech, C.; Seen, D.L.; Bégué, A. Assessing optical earth observation systems for mapping and monitoring temporary ponds in arid areas. Int. J. Appl. Earth Obs. Geoinf. 2009, 11, 344-351.

10. Li, W.; Du, Z.; Ling, F.; Zhou, D.; Wang, H.; Gui, Y.; Sun, B.; Zhang, X. A comparison of land surface water mapping using the Normalized Difference Water Index from TM, ETM+ and ALI. Remote Sens. 2013, 5, 5530-5549.

11. Zhao, D.; Lv, M.; Jiang, H.; Cai, Y.; Xu, D.; An, S. Spatio-temporal variability of aquatic vegetation in Taihu Lake over the past 30 years. PLoS One 2013, 8, e66365.

12. Davranche, A.; Lefebvre, G.; Poulin, B. Wetland monitoring using classification trees and SPOT-5 seasonal time series. Remote Sens. Environ. 2010, 114, 552-562.

13. Poulin, B.; Davranche, A.; Lefebvre, G. Ecological assessment of phragmites australis wetlands using multi-season SPOT-5 scenes. Remote Sens. Environ. 2010, 114, 1602-1609.

14. Shook, K.; Pomeroy, J.W.; Spence, C.; Boychuk, L. Storage dynamics simulations in prairie wetland hydrology models: Evaluation and parameterization. Hydrol. Process. 2013, 27, 1875-1889.

15. Crist, E.P.; Cicone, R.C. A physically-based transformation of Thematic Mapper data-The TM tasseled cap. IEEE Trans. Geosci. Remote Sens. 1984, 22, 256-263.

16. Ouma, Y.O.; Tateishi, R. A water index for rapid mapping of shoreline changes of five east African rift valley lakes: An empirical analysis using Landsat TM and ETM+ data. Int. J. Remote Sens. 2006, 27, 3153-3181.

17. Danaher, T.; Scath, P.; Armston, J.; Collett, L.; Kitchen, J.; Gillingham, S. Remote Sensing of Tree-Grass Systems: The Eastern Australian Woodlands. In Ecosystem Function in Savannas: Measurement and Modeling at Landscape to Global Scales; Hill, M.J., Hanan, N.P., Eds.; CRC Press: Boca Raton, FL, USA, 2010; pp. 175-194.

18. Flood, N.; Danaher, T.; Gill, T.; Gillingham, S. An operational scheme for deriving standardised surface reflectance from Landsat TM/ETM+ and SPOT HRG imagery for eastern Australia. Remote Sens. 2013, 5, 83-109.

19. Farr, T.G.; Rosen, P.A.; Caro, E.; Crippen, R.; Duren, R.; Hensley, S.; Kobrick, M.; Paller, M.; Rodriguez, E.; Roth, L.; et al. The shuttle radar topography mission. Rev. Geophys. 2007, doi: 10.1029/2005RG000183.

20. Gallant, J.; Read, A. Enhancing the SRTM Data for Australia. In Proceedings of Geomorphometry, Zurich, Switzerland, 31 August-2 September 2009.

21. Geoscience Australia. 1 Second SRTM Derived Digital Elevation Models User Guide; Version 1.0; Geoscience Australia: Canberra, ACT, Australia, 2010.

22. Robertson, K. Spatial transformation for rapid scan-line surface shadowing. IEEE Comp. Graph. Appl. 1989, 9, 30-38. 
23. Albanese, D.; Merler, S.; Jurman, G.; Visintainer, R.F.C. Mlpy-High-Performance Python Package for Predictive Modeling. Available online: http://mlpy.sourceforge.net/ (accessed on 15 July 2012).

24. Hastie, T.; Tibshirani, R.; Friedman, J.H. The Elements of Statistical Learning: Data Mining, Inference, and Prediction, 2nd ed.; Springer: New York, NY, USA, 2009; p. 758.

25. Bureau of Meteorology. Climate Data Online. Available online: http:/www.bom.gov.au/climate/ data (accessed on 19 September 2013).

(C) 2013 by the authors; licensee MDPI, Basel, Switzerland. This article is an open access article distributed under the terms and conditions of the Creative Commons Attribution license (http://creativecommons.org/licenses/by/3.0/). 